\title{
BMJ Open Parents' experience when their child has chronic abdominal pain: a qualitative study in Norway
}

\author{
Anne Brodwall, ${ }^{1}$ Kari Glavin, ${ }^{2}$ Per Lagerløv ${ }^{3}$
}

To cite: Brodwall A, Glavin $\mathrm{K}$, Lagerløv P. Parents' experience when their child has chronic abdominal pain: a qualitative study in Norway. BMJ Open 2018;8:e021066. doi:10.1136/ bmjopen-2017-021066

- Prepublication history for this paper is available online To view these files, please visit the journal online (http://dx.doi. org/10.1136/bmjopen-2017021066).

Received 8 December 2017 Revised 23 March 2018 Accepted 12 April 2018

\section{Check for updates}

1Department of Child and Adolescent Psychiatry, Vestre Viken Trust, Baerum, Norway ${ }^{2}$ Department of Health, VID Specialized University 0slo, Oslo, Norway

${ }^{3}$ Department of General Practice, Institute of Health and Society, University of Oslo, Oslo, Norway

Correspondence to

Dr Anne Brodwall;

abrodwa@online.no

\section{ABSTRACT}

Objective Functional abdominal pain occurs frequently in children and adolescents. It is an exclusion diagnosis; somatic diseases have to be ruled out. However little explanation is given for why the child is experiencing pain. The aim was to explore the experiences of parents of children with chronic abdominal pain discharged from hospital without a somatic explanation.

Design The study has a qualitative design. The open questions concerned pain experiences and management. Interviews were conducted at the hospital, at the parents' workplace or in their homes, audiotape recorded and transcribed. A descriptive content analysis was used to analyse the transcribed text.

Setting Parents of children referred from general practice located in urban and rural areas in two municipals in Norway.

Participants Fourteen parents of children with functional abdominal pain aged $5-15$ years.

Results Fourteen parents participated. Some explained that their child's disability glued the parents together on a common project to help the child. Other parents could tell that siblings got less attention and complained about too much fuss during pain. Parents wished for diagnosis that could be treated efficiently. Some were still anxious that an undetected condition triggered pain. They prompted their doctor to do further examinations. However some parents knew that social factors could inflict pain and were concerned that their child was unable to distinguish sensations like anxiety and 'butterfly' tensions from physical pain. The parents and children needed professional guidance on how to manage the pain . Conclusion The doctor's consultation should not end at the diagnosis of functional abdominal pain. Doctors may help these families further by focusing on pain management strategies.

\section{INTRODUCTION}

In 1958, John Apley, ${ }^{1}$ a British paediatrician, published his pioneering research in children with abdominal pain, which he labelled recurrent abdominal pain (RAP) syndrome. He found that $10.8 \%$ of British schoolchildren had RAP and stated, 'It is a fallacy that a physical symptom always has a physical cause and needs a physical treatment'. Since then, the term RAP has been replaced by
Strengths and limitations of this study

The individual interviews reveal that the whole family is affected when one child has chronic abdominal pain.

- Parents of children were interviewed when the children had just been discharged from hospital; this enabled recording the experiences before their memory had faded.

- The sample size was small, and only parents well-integrated into the society were approached; however we feel that their experience is transferable to many settings in general practice.

functional gastrointestinal disorders (FGIDs) as defined by the Rome criteria. ${ }^{1}$ FGIDs is characterised by chronic or recurrent digestive symptoms without an underlying somatic disease or biochemical abnormality. There are no biological markers of the condition, and the diagnosis is based exclusively on the symptoms reported by the child and parents. ${ }^{2}$ The Rome criteria have become an influential standard for defining FGIDs, which is the most common diagnosis among patients with gastrointestinal tract symptoms who consulted gastroenterologists and primary care physicians.

Bonilla and Sapps ${ }^{3}$ found that $38 \%$ of American schoolchildren and $35 \%$ of Columbian children reported weekly abdominal pain. A cross-sectional survey conducted in a school in Sri Lanka identified FGIDs in 28\% of the children. ${ }^{3}$ The prevalence rates of chronic abdominal pain among school-going children in the USA and Europe range from $0.3 \%$ to $19.0 \%{ }^{4}$ In almost $90 \%$ of these children, no explanatory organic cause can be identified. ${ }^{5}$ A study that reviewed the literature regarding the epidemiology of functional abdominal pain disorders in children found that they were a common problem worldwide. ${ }^{6}$

Chronic pain has a negative impact on the quality of life of children and adolescents, and their families. Mothers feel restricted in 
their social life and have problems dealing with the stress of their adolescents' pain. ${ }^{7}$ Chronic illness behaviour also appears to be learnt. ${ }^{8}$ Families of children with chronic pain generally have poorer family function than healthy populations. Pain-related disability is more consistently connected to family function than to pain intensity. ${ }^{9}$ Difficulties in the family may increase the frequency of pain in children, and their pain may in turn affect their parents and family life. ${ }^{10}$ Mothers of adolescents with functional abdominal pain were significantly more likely to have a lifetime history of irritable bowel syndrome, migraine, anxiety, and depressive or somatoform disorders compared with other mothers. ${ }^{11}$

The treatment of paediatric abdominal pain should attempt to focus on the influence of the parents. ${ }^{12}$ Parental responses to pain may be an important target for helping adolescents with their chronic pain. ${ }^{13}$ Exclusion of organic disorders is important for making the diagnosis of FGIDs ${ }^{14}$ after which it must be explained to the parents and the child/adolescent that further examination will not change the diagnosis or the available treatment. However, this situation may trigger suspicion in parents and a feeling that the medical establishment has failed. In many parts of Norway and probably in other countries the exclusion of somatic causes terminates the examination and follow-up by the specialist services and further support is expected to be given by the general practitioner (GP). Often the GP lacks support by specially trained healthcare personal like psychologists or nurses for these cases. This study examines different experiences reported by parents in handling RAP in one of their children. We want to know more about mother-child or child-parent relation to the pain, and the siblings' reactions to the problem.

The aim of our study was to explore the experiences of parents of children and adolescents with chronic abdominal pain who were discharged from hospital without a somatic explanation.

\section{METHODS}

A qualitative design with individual interviews was chosen. One aim was to condense single statements of experience into overarching concepts by text analysis of transcripts. By comparing comprehension by each researcher a common agreed understanding may be achieved. ${ }^{15} \mathrm{~A}$ semistructured interview guide was developed (box 1) comprising 10 open-ended questions and additional follow-up questions that allowed the interviewer to probe more deeply. ${ }^{16}$ The questions were developed after discussions and agreements within the interdisciplinary research team that had experience with children and adolescent patients. After two interviews, the guide was evaluated and some small modifications were made.

\section{Patient and public involvement statement}

There were no interactions with parents in developing the interview guide. The participants were informed that the results were to be published in an article.

\section{Box 1 Interview guide}

1. Could you tell about the last time your child had stomach pain?

2. How does your child react when he/she has stomach pain?

3. How do your spouse and the other children react when your child has stomach pain?

4. How do you experience the situation at home when your child has stomach pain?

5. Do you have some thoughts about the reason for your child's stomach pain?

6. What are you doing when your child has stomach pain?

7. How do you explain to your child about the stomach pain?

8. What did you experience the last time you visited the hospital with your child?

9. You have told me they did not find anything physically wrong with your child at the hospital. How did you feel about that?

10. Could you please explain your feelings about the follow-up at the hospital when all tests were normal?

11. Which country do you and your family come from?

12. What is the tradition in the country you come from in managing pain? Any differences from Norway?

13. What could make you feel more secure about your child's stomach pain?

14. Is there anything more you would like to add concerning your child's stomach pain?

15. How did you experience this interview?

\section{Recruitment}

We recruited participants referred to a hospital located in a mid-sized Norwegian town that covers 440000 inhabitants within the town and the surrounding area. Inclusion criteria: Children/adolescents 5-15 years old with abdominal pain, referred to hospital from a GP who had not found a diagnosis to the pain. Exclusion criteria: Inability to communicate in the Norwegian language. A dedicated nurse at the outpatient department recruited parents of children aged 5-15 years recently presenting with RAP.

She informed the parents about the study, handed out written information and obtained the phone numbers from those who wished to participate. The first author contacted the parents to arrange an interview. Fourteen parents were interviewed, and saturation was achieved. We did not identify new information by adding more participants. The recruitment was therefore stopped. ${ }^{17}$

\section{Interviews}

The first author, who is a female GP and child and adolescent psychiatrist, interviewed the parents. The parents knew that the interviewer was a physician; in the interview setting, however, she presented herself as a researcher with no therapeutic responsibility. The interviews were held in localities that suited the parents: one in the family's home, one at the parent's workplace, the other interviews at the author's office at the hospital. Different locations were approved to make it easier for these busy parents. All interviews were in a room with no disturbances. One interview was conducted by telephone. The interviews lasted $45-75 \mathrm{~min}$. 


\section{Data analysis}

The interviews were audiotape recorded and transcribed by the first author. Qualitative content analysis was conducted based on Graneheim and Lundman. ${ }^{16}$ All three authors read the transcripts individually while listening to the audiotape (ensuring a correct transcription) and worked together on their interpretation to achieve a common understanding and to reinforce the level of trust and credibility. ${ }^{16}$ We read the transcripts several times. The texts were sorted into meaning units, shortened and coded. Then the codes were categorised into subcategories and categories, form which the main themes emerged.

\section{RESULTS}

\section{Information about the interviewees}

In total 10 of the interview subjects were Norwegian. Four foreign parents had lived in Norway for several years and mastered the language well. All, except for two parents, lived together. The children with abdominal pain were 6-13 years old. Five fathers and 10 mothers were interviewed, both parents interviewed together in one family. In 13 families the child had siblings, nine children had one sibling, two children had two siblings and two children had four siblings.

\section{The main themes}

We identified three main themes: (1) How the pain rules the family. (2) The desire for a specific diagnosis and discussion with a professional. (3) Interpreting and handling the child's pain.

\section{How the pain rules the family}

Some parents reported that their child's pain affected the whole family. The strength and duration of the pain seemed to be factors that partly decided the degree to which the family life was changed. Major changes in their lives could result, such as deciding to stay out of work and/or not prioritising their social life: 'The whole family goes into another mode. We are around him and must adapt all our activities to him. We are thinking of this daily, every hour. It is the main subject of conversation between my wife and me'. Other families had to make some small adjustments to their everyday life. In some families, there was no significant change even if the child had pain; their life went on more or less the same: 'He decides if he wants to eat or not, but I don't think it affects us much'. The reactions among the siblings, reported by the parents, ranged from calling the affected child a drama queen to not noticing the pain at all: 'The brother can be irritated sometimes, he thinks there is a lot of fuss about this (pain) and suspects that sometimes she is pretending. Some of the parents in our study recognised the symptoms and the child's situation because they had experienced the same stomach pain themselves. Most parents were worried about their child's situation and that it affected all family members much: 'I show a great deal of care, but it is very difficult. I get irritated sometimes but cannot show it. We hear complaints from him every day and it is so exhausting'.

\section{Desire for a specific diagnosis and discussion with a professional}

All parents considered that a physical condition caused their children's stomach-aches. However, some parents were aware that stress at school or difficulties with friends impacted the child, perhaps triggering or causing pain: 'Our opinion is that it could be several factors, it gets worse during periods with school- or other social problems'. The parents reported frustration after their visits to hospital because they received no suggestions of ways to help the child. Parents expressed this annoyance differently: 'The doctors were good at informing us that these symptoms are not dangerous, but we know no more about the reasons for the pain. That is frustrating, but we must learn to live with it'.

The goal for most parents was to receive a medical diagnosis leading to a treatment that would make their child pain-free. Because this goal was not met, their child's pain continued to rule their daily life. Since there were no external causes to the child's aches, the parents felt that something was wrong with their parenting. They felt they are responsible for helping their child without knowing what to do.

They felt they were to be blamed, which was a very hurting experience: 'Yes, I am dictating the doctors, telling them what kind of medicine he should have and that we want to come back to the hospital. I must take the responsibility for getting medical help' and 'It is difficult and we despair because we do not know what we can do. If there had been a diagnosis, maybe it would have led to a treatment that would have helped. It is extremely sad and frustrating'. The pain was an important topic in the conversations between the parents. They reported wanting to consult a professional for both the child and the parents: 'It should be possible for parents who have children with chronic illnesses and no certain diagnosis to have a person to communicate with' and 'The only thing they could help him with is that he would have someone to talk to, so that he would not keep everything inside himself". Some parents wanted a quick fix or a healing tablet. They wanted their child to have further medical examinations, and that this should happen quickly: 'They could have examined more, because what if this is something very serious?'. Some parents also hoped that a medicine would soon become available that could remove the symptoms: "We hope that there will soon be a quick fix, a medicine that will solve the problem'.

\section{Interpreting and handling the child's pain}

Parents often tried to teach their child to distinguish pain from other sensations: 'A sensation of butterflies is not the same as stomach pain, but she has a tendency to call everything stomach pain'. When the child had days with severe pain, the parents dealt with the situation in different ways: 'She must go to the toilet; she is not getting any painkillers and she must learn to avoid the food she is reacting to'. The parents reported that the sisters and brothers also showed different reactions: 'We usually do not get involved-. It is 
not so bad that we need to adapt our lives to this, but she must just learn to live with it'. Some parents were afraid to be viewed as 'hysterical mothers'. They said that they understood that these thoughts and feelings were something they produced themselves, but they still feared not being taken seriously by the doctors. One parent reported that the child did not want to talk about the pain: 'He looks away, listens to YouTube, and he will not communicate with us. He puts on earplugs and lets the time flow away'. Some families gathered to watch films or television together when the child had stomach pain because they felt that it reduced the attention to the pain: 'We skip sport or exercise that day, instead we relax at home together. We ask her what she wants to do, try to calm her down, watch a film together, play cards and try to distract her from the pain'.

\section{DISCUSSION}

Parents of children with RAP recently discharged from hospital without an identified somatic cause felt frustrated because they did not receive specific help. They wanted a somatic explanation and a treatment that could solve the problem and alleviate their responsibility for a child in pain. They often reported that in a way, because of the child's condition the whole family's focus was on managing the pain. Sometimes they needed to help their child to understand that some somatic sensations were not caused by disease but by tensions such as joy or anxiety. The parents expressed they wished to have professionals with whom they could discuss their perceived shortcomings in caretaking and to guide the child on ways to live with their painful condition.

\section{How the pain rules the family}

Some families went into a new mode of living during the pain episodes. In these families, the question of how to manage and react to the pain was a topic commonly discussed between the parents. Therefore, the pain acted in a way like glue, uniting the husband and wife in solving a common problem. However, Michael Balint ${ }^{18}$ wrote, 'A functional illness means that the patient has had a problem that he tried to solve with an illness. The illness enabled him to complain, whereas he was unable to complain about his original problem'. Perhaps the pain may be an unexpressed way for the child to handle family conflicts. Lewandowski et at reported that families of children with chronic pain generally have poorer family functioning than healthy populations. In our study, some siblings confronted their parents to state that the pain of their brother or sister overwhelmed the family life and drew attention away from their normal activities. Others have found that siblings of children in pain often experienced more emotional or behavioural symptoms than their peers, and that parents did not readily identify these symptoms. ${ }^{19}$ One parent in our study reported that their son complained that his sister was pretending to have pain. Therefore, the pain may both unite and divide the family depending on whether other members accept or deny that the child is in pain.

\section{Desire for a specific diagnosis and conversation with a professional}

The outcome most wanted by parents after examinations were detection of a somatic disease with a well-defined treatment. No explanation or a vague description of the biopsychosocial model ${ }^{13}$ was not satisfying. This model may even give the parents the feeling that they are partly responsible for the condition and feel ashamed of not being able to find a solution. The anxiety that something dangerous may be overlooked may make the parents crave further examinations. Smart et $a l^{20}$ stated that the mothers needed to be certain they were not missing a physical illness before they could concentrate on a psychological explanation. A vicious cycle of hunting for an understandable explanation may arise, which puts strain on both the child and the parents.

Parents reported that they missed having a doctor to whom they could express their difficulties. If doctors were available for consultation at an early stage in the series of pain scenarios, perhaps the conditions could be prevented or aborted. Changing parents' and children's perceptions of the condition, expressed as abdominal pain, is just the focus of cognitive behavioural therapy. Recently such therapy has been reported to be effective in influencing symptoms and slowly changing behavioural patterns. ${ }^{21}$ To change the parents' responses to this pain, even a brief phone call applying social learning and cognitive behavioural therapy, instead of an impersonal contact, could be effective..$^{22}$

'A sensation of butterflies in the stomach are not the same as stomach pain' was the claim by one of the parents. She explained to her child that tension and joy caused this sensation; this feeling is not pain and does not need painkillers. The expression of bodily sensations needs interpretation and guidance from parents mirroring their reactions back to the child. ${ }^{23}$ This is a difficult task and depends on the child's age and vocabulary. That a middle ear infection in small children may present itself as stomach pain is an example of the difficulty in interpreting discomfort, especially in small children. Perhaps the parents' own experience of pain is reflected back to the child as a reaction to the child's discomfort. Mothers with chronic pain were five times more likely to report pain in their child than mothers without pain. ${ }^{24}$ Sometimes parents' perception of and reaction to the child's pain may be counterproductive in the long term, although in the short term it may facilitate a protective relationship. ${ }^{25}$ The reactions described by our parents ranged from ignoring the pain to almost overinvolvement. Many parents deviated from their daily routines during pain episodes, for instance, by making special food or gathering in front of the television. This may constitute a reward. Parents who downplayed the discomfort may be anxious not to aggravate the condition. Another study has shown that some mothers felt a responsibility not to give 
in to the symptoms of their child because they could be held accountable for sustaining the disability. ${ }^{20}$

\section{Strengths and limitations}

The interviewer and first author is herself a GP and child psychiatrist, although she introduced herself as a scientist without responsibility for taking care of the family. She ensured that the family was already taken care of by the healthcare system. Full privacy was ensured although the interviews were conducted in different settings. The informants who took part in our study should be representative of families in Norway. However, we did not recruit many parents with a foreign background. Because we mainly interviewed Norwegians, some precautions are needed in transferring the experiences identified in our study to other populations. Although our informants were recruited from an outpatient hospital setting, the threshold for GPs to refer children with pain to hospital is low, and we believe that the situations described by our parents are relevant for general practice.

\section{CONCLUSION}

Children with FGIDs are referred back to their GPs after discharge from hospital without evidence of serious somatic disease. However, the parents and the child may be left without any guidance about how to manage the recurrent pain. Focusing on the pain could drive the family and the doctor into a vicious cycle of hunting for undetected causes instead of focusing on pain management. Functional pain is a challenging subject. These families need a caring physician with the time and interest for discussing and excluding other diagnoses. Psychoeducation about the pain and strategies on how to handle the pain in daily life are also an important part of the treatment. Cognitive behavioural therapy may be one suggestion for helping patients with FGIDs and their families, although other treatments should also be examined. Further research is needed to help the families of children who receive a diagnosis of FGIDs.

Acknowledgements The authors thank all parents who shared their experiences with them.

Contributors The paper was conceived by $A B, K G$ and PL. AB wrote the first draft, with further contributions from all authors. Questionnaire design, ethics applications and piloting were undertaken by $A B$. All authors contributed to data interpretation, reviewed successive drafts and approved the final version of the manuscript.

Funding The study was supported by grants from The Norwegian Committee on Research in General Practice (2016/11 and 2015 /11)

Competing interests None declared.

Patient consent Parental/guardian consent obtained.

Ethics approval The Regional Committees for Medical and Health Research Ethics in Norway approved the study (reference no. 2015/1928). The study has followed the operational principles of the Declaration of Helsinski and has adhered to the Belmont Report principles (respect for persons; beneficence; and justice) when obtaining valid informed consent from parents.

Provenance and peer review Not commissioned; externally peer reviewed.

Data sharing statement The data set is not available.
Open Access This is an Open Access article distributed in accordance with the Creative Commons Attribution Non Commercial (CC BY-NC 4.0) license, which permits others to distribute, remix, adapt, build upon this work non-commercially, and license their derivative works on different terms, provided the original work is properly cited and the use is non-commercial. See: http://creativecommons.org/ licenses/by-nc/4.0/

(C) Article author(s) (or their employer(s) unless otherwise stated in the text of the article) 2018. All rights reserved. No commercial use is permitted unless otherwise expressly granted.

\section{REFERENCES}

1. Apley J, Naish N. Recurrent abdominal pains: a field survey of 1,000 school children. Arch Dis Child 1958;33:165-70.

2. Rasquin A, Di Lorenzo C, Forbes D, et al. Childhood functional gastrointestinal disorders: child/adolescent. Gastroenterology 2006;130:1527-37.

3. Bonilla S, Saps M. Early life events predispose the onset of childhood functional gastrointestinal disorders. Rev Gastroenterol Mex 2013;78:82-91.

4. Chitkara DK, Rawat DJ, Talley NJ. The epidemiology of childhood recurrent abdominal pain in Western countries: a systematic review. Am J Gastroenterol 2005;100:1868-75.

5. Spee LA, Lisman-Van Leeuwen Y, Benninga MA, et al. Prevalence, characteristics, and management of childhood functional abdominal pain in general practice. Scand J Prim Health Care 2013;31:197-202.

6. Korterink JJ, Diederen K, Benninga MA, et al. Epidemiology of pediatric functional abdominal pain disorders: a meta-analysis. PLoS One 2015;10:e0126982-17.

7. Hunfeld JA, Perquin CW, Duivenvoorden HJ, et al. Chronic pain and its impact on quality of life in adolescents and their families. $J$ Pediatr Psychol 2001;26:145-53.

8. Whitehead WE, Winget C, Fedoravicius AS, et al. Learned illness behavior in patients with irritable bowel syndrome and peptic ulcer. Dig Dis Sci 1982;27:202-8.

9. Lewandowski AS, Palermo TM, Stinson J, et al. Systematic review of family functioning in families of children and adolescents with chronic pain. J Pain 2010;11:1027-38.

10. Palermo TM. Impact of recurrent and chronic pain on child and family daily functioning: a critical review of the literature. J Dev Behav Pediatr 2000;21:58-69.

11. Campo JV, Bridge J, Lucas A, et al. Physical and emotional health of mothers of youth with functional abdominal pain. Arch Pediatr Adolesc Med 2007;161:131-7.

12. Van Der Veek SM, Derkx HH, De Haan E, et al. Do parents maintain or exacerbate pediatric functional abdominal pain? A systematic review and meta-analysis. $J$ Health Psychol 2012;17:258-72.

13. Simons LE, Claar RL, Logan DL. Chronic pain in adolescence: parental responses, adolescent coping, and their impact on adolescent's pain behaviors. J Pediatr Psychol 2008;33:894-904.

14. Korterink J, Devanarayana NM, Rajindrajith S, et al. Childhood functional abdominal pain: mechanisms and management. Nat Rev Gastroenterol Hepatol 2015;12:159-71.

15. Kvale S, Brinkmann S. Interview-introduction to a craft. Copenhagen: Hans Reitzels Forlag, 2009.

16. Graneheim UH, Lundman B. Qualitative content analysis in nursing research: concepts, procedures and measures to achieve trustworthiness. Nurse Educ Today 2004;24:105-12.

17. Malterud K, Siersma VD, Guassora AD. Sample size in qualitative interview studies: guides by information power. Qual Health Res 2015;26:1753-60.

18. Balint M. ChapterXX general- practitioner psychtherapy. The doctor. His patient and the illness. 2nd edn. Edinburgh: Churchill Livingstone, 1986:273.

19. Guite JW, Lobato DJ, Shalon L, et al. Pain, disability, and symptoms among siblings of children with functional abdominal pain. J Dev Behav Pediatr 2007;28:2-8.

20. Smart S, Cottrell D. Going to the doctors: the views of mothers of children with recurrent abdominal pain. Child Care Health Dev 2005;31:265-73.

21. Levy RL, Langer SL, Romano JM, et al. Cognitive mediators of treatment outcomes in pediatric functional abdominal pain. Clin $\mathrm{J}$ Pain 2014;30:1033-43.

22. Levy RL, Langer SL, van Tilburg MA, et al. Brief telephone-delivered cognitive behavioral therapy targeted to parents of children with 
functional abdominal pain: a randomized controlled trial. Pain 2017;158:618-28.

23. McGrath PA, Hillier L. Modifying the psychologic factors that intensify children's pain and prolong disability. In: Schlechter N, Berde C,

Yaster M, eds. Pain in infants, children and adolescents. 2nd edn. Philadelphia: Lippincott Williams and Wilkins, 2002:85-104.
24. Graungaard AH, Siersma V, Lykke K, et al. Maternal pain influences her evaluation of recurrent pain in 6- to 11-year-old healthy children. Acta Paediatr 2016;105:183-90.

25. Morris A, Ogden J. Making sense of childrens medically unexplained symptoms: managing ambiguity, authenticity and responsibility. Psychol Health Med 2012;17:285-94. 